\title{
Adult attachment: What are the underlying dimensions?
}

\author{
Helen Stein*, A. Dawn Koontz, Peter Fonagy, Jon G. Allen, \\ Jim Fultz, John R. Brethour, Jr., Darla Allen and Richard B. Evans
}

Child and Family Center, The Menninger Clinic, Topeka, Kansas, USA

\begin{abstract}
Using a community sample of I I 5 young adults, this study applied a range of statistical techniques to five measures of adult attachment to gain a better understanding of what they assess. First, we determined comparability of measures, using both categorical and dimensional approaches to model the association. Agreement among classifications was modest. Next, we examined the relation of attachment classifications and attachment measure subscale scores to criterion variables (i.e. dyadic adjustment, interpersonal sensitivity and severity of psychiatric symptoms). Classification predicted severity of psychological symptoms better than it predicted other measures of adjustment. Finally, using a principal components analysis, we mapped the relationship among underlying constructs, the subscales of the five measures and three criterion measures of psychological adjustment. We discuss our findings from the perspective of underlying constructs of attachment insecurity and strategy for coping with insecurity in relationships, noting implications for further research.
\end{abstract}

Most self-report measures of adult attachment borrow from concepts described by John Bowlby (1969/1982), demonstrated by laboratory studies of infants' reactions to maternal separations (Ainsworth, Blehar, Waters, \& Wall, 1978) and extended to adulthood in the Adult Attachment Interview (AAI; George, Kaplan, \& Main, 1996). While the participant's state of mind with respect to childhood experiences with parents is the basis for AAI classifications, most self-reports ask about thoughts and feelings in adulthood, usually with respect to romantic partners. The resulting classifications correspond roughly to Ainsworth's original three infant classifications: secure, avoidant and resistant. Bartholomew (1990) has suggested four categories of adult attachment: secure, dismissing, preoccupied and fearful. She made an important distinction between dismissing individuals, who avoid attachment because they do

Requests for reprints should be addressed to Helen Stein, PhD, Menninger, Box 829, Topeka, KS 6660I-0829, USA (e-mail:steinhb@menninger.edu). 
not value it, and fearful individuals, who long for but avoid intimacy because they fear rejection.

Several writers on adult attachment have discussed the advantages of a dimensional over a categorical approach (Fonagy, 1999; Fraley \& Waller, 1998; Hazan \& Shaver, 1994; Rutter, 1995). Although much of the research on adult attachment relies on a language of categories that are descendants of infant attachment classifications, most self-report measures actually measure adult attachment in terms of continuous dimensions. Brennan, Clark, and Shaver (1998) note that Ainsworth et al. (1978) explained infant attachment patterns on the basis of two underlying dimensions, avoidance and anxiety, which also appear to underlie adult attachment styles. However, as Fraley and Waller (1998) observe, Ainsworth et al. retained the classificatory groups to communicate important behaviour patterns and their developmental underpinnings. Even the AAI yields a number of subcategories that span a continuum. Fraley and Waller (1998) used taxometric procedures to analyse responses of college students to Griffin and Bartholomew's (1994) Relationship Scales Questionnaire. Taxometric techniques are designed specifically to investigate the continuous vs. discrete nature of variables. The authors demonstrated that dimensional models fit the data of adult attachment (as represented by Relationship Scales Questionnaire responses) better than typological models.

Comparative studies of adult attachment measures suggest that different measures converge if they use the same method and conceptual framework and focus on the same domain (Bartholomew \& Shaver, 1998; Sperling, Foelsch, \& Grace, 1996). As mentioned earlier, several measures now posit the same underlying dimensions and/or yield the same four-way classification system. Nonetheless, confusion remains about what the questionnaires actually measure: adult attachment behaviours or expectations and wishes about forming relationships, an individual trait present across most relationships or a state of mind that is at least partly relationship-specific.

To gain a clearer idea of what attachment questionnaires measure, we compared five self-report measures with the potential to yield four categories: secure, dismissing, preoccupied and fearful. Three measures ask about a general target, 'relationships in general' or 'close relationships', while two ask about romantic relationships. We administered these measures, a checklist of psychiatric symptoms and a measure of dyadic adjustment to a community sample of 115 participants. First, taking a categorical approach, we examined four-way (secure-dismissing-preoccupied-fearful) disagreement rates across measures by converting participants' scores into attachment categories. We also compared the ability of categories across measures to predict scores on criterion variables: a global index of severity of psychiatric symptoms, the Global Severity Index (GSI) of the Brief Symptom Inventory (BSI; Derogatis, 1993); a measure of interpersonal sensitivity, the Interpersonal Sensitivity subscale (IST) of the BSI; and a measure of relationship satisfaction, the Dyadic Adjustment Scale (DAS; Spanier, 1976). Using a dimensional approach, we conducted a principal components analysis to explore convergence among different measures. Finally, we mapped the relationship of attachment subscales to criterion variables. We hoped to answer the following questions:

(1) Using a four-way classification system, do these attachment questionnaires categorize participants similarly? Do measures with specific targets (romantic relationships) categorize participants more similarly than measures with more general targets (close relationships or relationships in general)?

(2) Are there specific associations between underlying dimensions of attachment 
and specific domains of individual differences, such as severity of psychiatric symptoms, interpersonal sensitivity and dyadic adjustment?

(3) Do relationships among subscales suggest common underlying dimensions?

\section{Method}

\section{Participants}

The following information was obtained from a brief demographics questionnaire administered to 115 male and female residents of two small Midwestern cities. Because the study involved a scale of dyadic adjustment, only individuals who had been in a relationship lasting six months or longer were invited to participate. The mean age of the sample was $23.7(\mathrm{SD}=4.2)$. In terms of gender, $74.8 \%(N=86)$ were female, $25.2 \%(N=29)$ male. With respect to marital status, $52.2 \%$ were in a non-cohabiting serious relationship, $24.3 \%$ cohabiting, $19.1 \%$ married, and $4.3 \%$ self-described as single. Education varied from 'some high school' to 'graduate degree', with $53.9 \%$ having attended and $33 \%$ having graduated from college. All participants were asked to designate the closest other person (attachment figure) in their life, from whom they would seek reassurance or comfort. Partner or spouse was the primary attachment figure for $79.2 \%$ of the participants.

Because the sample was not evenly divided by gender and analyses by gender yielded no significant differences except for one subscale, data were collapsed across gender and analysed in toto.

\section{Measures}

\section{Attachment questionnaires}

Revised Adult Attachment Scale (RAAS; Collins E Read, 1990). This 18 item questionnaire asks participants to rate their 'feelings about romantic relationships' on a 5-point Likert scale, yielding three scores: comfort with closeness (close), capacity to depend on others (depend) and fear of being abandoned (anxiety). A scoring protocol converts dimensional scores into four categories (secure, preoccupied, dismissing and fearful) based on relationships between subscales and categories (Collins, 1996).

17-item Adult Attachment Scale (AAS; Simpson, 1990). This questionnaire asks participants to rate their feelings 'toward romantic (dating) partners in general' on a 7-point scale. It yields scores on avoidance and anxious-ambivalence. Using Collins's (1996) scoring system as a model, we assumed that secure participants would score relatively low on ambivalence and avoidance. Starting from the median score on each scale, we chose cut-off points that would place approximately $53 \%$ of the participants below these points. We anticipated that secure participants would have low ambivalence and low avoidance; preoccupied participants would score high on ambivalence and low on avoidance; dismissing participants would score high on avoidance and low on ambivalence; and fearful participants would score high on both subscales.

Relationship Questionnaire (RQ; Bartholomew E Horowitz, 1991). This adaptation and expansion of Hazan and Shaver's (1987) Adult Attachment Questionnaire yields dimensional scores on four categories of attachment. Participants rate attachment prototypes corresponding to the categories secure, dismissing, preoccupied and fearful, according to the 'extent to which... each description corresponds to your general relationship style'. In Bartholomew and Horowitz's original version, participants choose the prototype description that best fits how they perceived

\footnotetext{
I The scales that could be directly scored for classifications (RQ, RSQ and RAAS) yielded these percentages of secure participants: $50 \%, 48 \%$ and $60 \%$ respectively. We averaged these percentages and applied the mean, $53 \%$, to create four-way classifications for the AAS and the ASQ.
} 
themselves in close relationships, rating each on a 7-point scale. We modified the questionnaire by asking participants to rate each style between 0 and 100 , without giving the same number twice. We categorized each participant using the prototype with the highest rating.

Relationship Scales Questionnaire (RSQ; Griffin E Bartholomew, 1994). This scale includes 30 items that describe 'feelings about close relationships'. Participants rate statements on a 5 -point Likert scale. The scale items represent an amalgam of other self-report measures. For example, some items correspond to phrases in Hazan and Shaver's (1987) attachment measure and to statements from the RAAS. The RSQ yields scores on six subscales but can also be scored for four attachment categories (secure, preoccupied, dismissing and fearful) by computing the mean score for items representing each prototype (Griffin \& Bartholomew, 1994). We assigned one of four categories to participants based on their highest category score.

Attachment Style Questionnaire (ASQ; Feeney, Noller, E Hanrahan, 1994). This 40-item questionnaire asks participants to rate aspects of themselves and others on a 6-point Likert scale. It asks, by implication, about relationships in general rather than romantic or close relationships. It yields five subscales: confidence, discomfort with closeness, relationships as secondary, need for approval, and preoccupation with relationships. These subscales can be understood using the concepts of avoidance and anxiety: discomfort with closeness and relationships as secondary reflect avoidance; need for approval, preoccupation with relationships, and (low) confidence reflect anxiety. Feeney, Noller, and Hanrahan (1994) endorse Bartholomew's fourway classification of attachment styles, based on latent factors of self and other, and demonstrate it with a cluster analysis but do not provide a scoring protocol for classification. To convert dimensional scores into four categories, we created a protocol modelled on the Collins's protocol for the RAAS (described in Stein et al., 2000).

\section{Adjustment questionnaires}

Dyadic Adjustment Scale (DAS; Spanier, 1976). This 38 item questionnaire asks participants to rate extent of agreement/disagreement with partners' views on a number of issues, including finances, religion, sex and household tasks. It also asks about the quantity and type of contact (e.g. physical affection, working on a project together) and conflict. The scale yields a single score, ranging from 0 to 151, that indicates an individual's relationship satisfaction; higher scores reflect greater satisfaction. We hypothesized that secure participants, with lower scores on anxiety and avoidance, would have higher scores on dyadic adjustment. There is evidence for a relationship between secure attachment and relationship satisfaction among couples who are dating (Collins \& Read, 1990; Kirkpatrick \& Davis, 1994, Simpson, 1990) or married (Feeney, 1994; Feeney, Noller \& Callan, 1994). The mean of sample raw scores on the DAS was $110.83(\mathrm{SD}=17.81)$.

Brief Symptom Inventory (BSI; Derogatis, 1993). This 53 item questionnaire yields nine symptom scales and an overall mean, the Global Severity Index (GSI), which indicates participants' overall severity of psychopathology. For this study, we selected two scales, GSI and Interpersonal Sensitivity (IST), converting raw scores to $t$-scores with a mean of 50 and a standard deviation of 10 . We hypothesized that preoccupied and fearful individuals would endorse greater interpersonal sensitivity (more likely to feel hurt, inferior, self-conscious or disliked). Collins (1996) found positive associations between preoccupied/fearful attachment and negative interpretations of partners' acts; according to Simpson, Rholes, and Phillips (1996), ambivalent women see their partner and their relationship in a negative light after trying to resolve a problem. The other scale of interest was the GSI. We expected secure and dismissing participants to be less likely to endorse psychiatric symptoms than participants with preoccupied and/or fearful attachment. Cooper, Shaver, and Collins (1998) found that secure adolescents scored lower than avoidant or ambivalent adolescents on every BSI scale. However, ambivalent adolescents scored higher than avoidant adolescents on depression and hostility items. Dozier and Lee (1995) 
note that individuals using dismissing attachment strategies consistently report less psychopathology than individuals with preoccupied attachment strategies. The mean of the sample $t$ scores on the GSI was $57.5(\mathrm{SD}=9.74)$. The mean of sample $t$ scores on the IST was $57.12(\mathrm{SD}=10.08)$.

\section{Procedures}

Recruitment flyers were distributed at two universities, a vocational school, coffee shops, a health club, a government office building and a social services office. Individuals who called to express an interest in participating were scheduled for an appointment with a research assistant, who described the study and inclusion criteria and obtained informed consent. Participants then completed the questionnaires while sitting alone in an interview room, taking about an hour to complete all measures. They were paid for their time at the end of the session.

\section{Results}

\section{Distributions of attachment classifications}

For the three measures that yielded attachment classifications, the percentages of secure participants were $48 \%(N=53)$ for the RSQ, $51 \%(N=58)$ for the RQ, and $63 \%(N=68)$ for the RAAS. The percentages of dismissing participants were $22 \%(N=24)$ for the RSQ, $13 \%(N=15)$ for the RQ, and $11 \%(N=12)$ for the RAAS. The percentages of preoccupied participants were $15 \%(N=17)$ for the RSQ, $8 \%(N=9)$ for the RQ, and $13 \%(N=14)$ for the RAAS. The percentages of fearful participants were $15 \%(N=16)$ for the RSQ, $28 \%(N=32)$ for the RQ, and $13 \%(N=14)$ for the RAAS. The percentages of participants categorized as secure by the AAS and the ASQ were predetermined. However, the relative percentages of participants categorized as dismissing $(17 \%)$ and fearful $(11 \%)$ were identical for both measures. We classified $19 \%(N=22)$ of the participants as preoccupied on the AAS vs. $13 \%(N=13)$ on the ASQ. Thus, the RAAS was more likely than other measures to classify participants as secure, and the RQ was about twice as likely as other measures to classify participants as fearful. ${ }^{2}$

\section{Analysis of disagreement rates}

To evaluate how consistently participants were classified using the attachment measures, we calculated disagreement rates across the five questionnaires. We assessed disagreement using four-way classifications (secure, dismissing, preoccupied and fearful), as described in the Methods section. Unclassifiable cases were omitted from analysis.

The RQ, RSQ and RAAS yielded four attachment categories. As described earlier, we forced four categories from the AAS and the ASQ. We then crosstabulated these for each pair of measures and compared disagreement rates (see Table 1). The disagreement rate for the RSQ and RQ, the most conceptually similar measures, which query relationships in general, is $35 \%$, just above the middle of the range. The disagreement rate for the two measures that inquire about romantic relationships, the RAAS and AAS, is $21 \%$.

\footnotetext{
${ }^{2}$ The high rate of participants classified as fearful on the RQ probably is related to a 'hedge word', sometimes, in the fearful description: 'I sometimes worry that others don't value me as much as I value them.'
} 
Table I. Four-way (secure/dismissing/preoccupied/fearful) attachment classification disagreement rates and kappas for five measures of adult attachment

\begin{tabular}{llcrrr}
\hline & AAS & ASQ & RAAS & RQ & RSQ \\
\hline AAS & & .27 & .21 & .42 & .43 \\
ASQ & $\kappa=.55$ & & .19 & .38 & .30 \\
RAAS & $\kappa=.64$ & $\kappa=.67$ & & .33 & .36 \\
RQ & $\kappa=.36$ & $\kappa=.41$ & $\kappa=.48$ & & .35 \\
RSQ & $\kappa=.35$ & $\kappa=.53$ & $\kappa=.43$ & $\kappa=.48$ & \\
\hline
\end{tabular}

Note. All kappas are significant at $p<.001$.

\section{Validity of attachment categories}

In the second set of analyses, we attempted to validate attachment categories by examining their association with severity of psychiatric symptoms (GSI), interpersonal sensitivity (IST) and relationship satisfaction (DAS). To model the association, we performed a series of analyses of variance using four-way classifications derived for each measure (secure/dismissing/preoccupied/fearful) as the independent variables, and GSI, IST and DAS as the criterion variables. Overall, attachment categories were significantly associated with GSI, IST and DAS, but associations with psychiatric symptoms were most powerful ( $F$ s for ANOVAs with GSI as the criterion variable were larger for every measure). Post-hoc tests of pairwise contrasts (Student-New manKeuls) of attachment categories were performed (see Table 2).

Depending on the measure, certain categories discriminated adjustment better than others. For the two most discriminating measures (ASQ and RAAS), in contrast to dismissing, preoccupied and fearful attachment, secure attachment was associated with significantly lower GSI scores (i.e. better functioning). The secure category on both was also associated with lower IST scores than was fearful or preoccupied. However, participants categorized as dismissing on the ASQ had significantly lower scores on IST than the fearful or preoccupied participants; participants categorized as dismissing on the RAAS did not. Participants categorized as secure on the ASQ and RAAS reported significantly higher DAS scores than fearful participants. However, dismissing and preoccupied participants (RAAS) also reported significantly higher DAS scores (i.e. better adjustment) than fearful participants.

\section{Synthesizing results by component mapping}

To synthesize results and more clearly demonstrate relationships among subscales, we performed a principal components analysis of all 18 subscale scores for the five adult attachment measures. A two-component solution accounted for all eigenvalues greater than 1.0 and for $66 \%$ of the total variance. We then constructed a componentloading plot for the two-component unrotated solution and mapped the three criterion variables, GSI, IST and DAS, onto the plot.

Our rationale was that component loading can be interpreted as the correlations of items in the analysis with the component scores for the extracted components. The coordinates for items in a component loading plot are equivalent to correlations of items with the component scores (Harman, 1967). Therefore, to depict the relations of 
Table 2. Means (SDs) on global severity, interpersonal sensitivity, and dyadic adjustment for participant classifications using five adult attachment measures

Criterion variables

\begin{tabular}{|c|c|c|c|c|c|c|c|c|}
\hline \multirow{2}{*}{$\begin{array}{l}\text { Measures } \\
\text { AAS }\end{array}$} & \multirow{2}{*}{$\begin{array}{l}\begin{array}{l}\text { Attachment } \\
\text { classification }\end{array} \\
\text { Secure }\end{array}$} & \multirow{2}{*}{$\frac{N}{62}$} & \multicolumn{2}{|c|}{ GSI: $t$ scores } & \multicolumn{2}{|c|}{ IST: $t$ scores } & \multicolumn{2}{|c|}{ DAS scores } \\
\hline & & & $54.08^{a b c}$ & $(10.15)$ & $54.26^{a}$ & $(9.69)$ & 115.80 & $(|3.3|)$ \\
\hline & Dismissing & 19 & 61.26 & $(6.81)$ & $56.53^{f}$ & $(10.00)$ & 103.47 & $(23.10)$ \\
\hline & Preoccupied & 22 & 60.94 & $(6.65)$ & 60.74 & (8.69) & 106.23 & $(19.81)$ \\
\hline & Fearful & 12 & 63.33 & $(10.01)$ & 64.58 & $(10.02)$ & 105.25 & $(17.81)$ \\
\hline & Overall effect & & \multicolumn{2}{|c|}{$\begin{array}{c}F(3, I I I)=6.72 \\
p<.0 I\end{array}$} & \multicolumn{2}{|c|}{$\begin{array}{c}F(3, I I I)=4.96 \\
p<.01\end{array}$} & \multicolumn{2}{|c|}{$\begin{array}{c}F(3, I I I)=3.84 \\
p<.02\end{array}$} \\
\hline
\end{tabular}

\begin{tabular}{|c|c|c|c|c|c|c|c|c|}
\hline \multirow[t]{5}{*}{ ASQ } & Secure & 66 & $53.80^{a b c}$ & $(9.26)$ & $53.61^{a c}$ & $(9.46)$ & $116.46^{a}$ & (I2.26) \\
\hline & Dismissing & 19 & 60.63 & $(8.16)$ & $57.74^{d f}$ & $(8.91)$ & 107.89 & (I8.65) \\
\hline & Preoccupied & 15 & 62.78 & $(5.93)$ & 64.22 & $(6.03)$ & 104.67 & (22.39) \\
\hline & Fearful & 12 & 65.75 & (9.74) & 65.08 & $(10.75)$ & 98.17 & (21.72) \\
\hline & Overall effect & & \multicolumn{2}{|c|}{$\begin{array}{c}F(3,108)=10.07 \\
p<.01\end{array}$} & \multicolumn{2}{|c|}{$\begin{array}{c}F(3,108)=9.32 \\
p<.001\end{array}$} & \multicolumn{2}{|c|}{$\begin{array}{c}F(3,108)=6.00 \\
p<.001\end{array}$} \\
\hline \multirow[t]{5}{*}{ RAAS } & Secure & 68 & $53.57^{a b c}$ & (8.53) & $53.69^{a c}$ & (9.16) & $115.64^{a}$ & (I3.87) \\
\hline & Dismissing & 12 & 61.83 & (7.67) & 58.00 & $(9.17)$ & $108.17^{f}$ & (I5.43) \\
\hline & Preoccupied & 14 & 63.41 & $(7.91)$ & 63.38 & $(9.52)$ & $110.86^{e}$ & (20.24) \\
\hline & Fearful & 14 & 64.64 & $(9.5 \mathrm{I})$ & 64.36 & $(8.64)$ & 91.57 & $(23.66)$ \\
\hline & Overall effect & & \multicolumn{2}{|c|}{$\begin{array}{c}F(3,104)=11.39 \\
p<.001\end{array}$} & \multicolumn{2}{|c|}{$\begin{array}{c}F(3,104)=8.29 \\
p<.001\end{array}$} & \multicolumn{2}{|c|}{$\begin{array}{c}F(3,104)=8.44 \\
p<.001\end{array}$} \\
\hline \multirow[t]{5}{*}{ RQ } & Secure & 58 & $53.96^{a c}$ & $(9.36)$ & $54.37^{c}$ & $(9.48)$ & 115.07 & (I4.7I) \\
\hline & Dismissing & 15 & $57.93^{d}$ & (8.32) & $54.13^{d}$ & (8.74) & 112.13 & $(9.55)$ \\
\hline & Preoccupied & 9 & 65.56 & $(4.93)$ & $67.89^{e}$ & $(5.01)$ & 101.78 & $(25.47)$ \\
\hline & Fearful & 32 & 62.13 & $(8.77)$ & 60.97 & (9.56) & 104.82 & (21.50) \\
\hline & Overall effect & & \multicolumn{2}{|c|}{$\begin{array}{c}F(3, I I 0)=8.55 \\
p<.001\end{array}$} & \multicolumn{2}{|c|}{$\begin{array}{c}F(3, I \mid 0)=8.30 \\
p<.001\end{array}$} & \multicolumn{2}{|c|}{$\begin{array}{c}F(3, I \mid 0)=3.28 \\
p<.03\end{array}$} \\
\hline \multirow[t]{5}{*}{ RSQ } & Secure & 53 & $52.64^{a b c}$ & (7.87) & $53.06^{a c}$ & $(8.66)$ & $115.93^{a}$ & (I2.70) \\
\hline & Dismissing & 24 & 59.75 & (10.49) & $56.21^{d f}$ & (10.32) & 109.79 & (I6.29) \\
\hline & Preoccupied & 17 & 62.34 & $(8.39)$ & 63.25 & $(9.59)$ & |08.7| & (22.77) \\
\hline & Fearful & 16 & 63.69 & $(8.46)$ & 64.19 & (8.7I) & 98.06 & (23.08) \\
\hline & Overall effect & & \multicolumn{2}{|c|}{$\begin{array}{c}F(3, I \mid 0)=10.57 \\
p<.001\end{array}$} & \multicolumn{2}{|c|}{$\begin{array}{c}F(3,1 \mid 0)=9.19 \\
p<.001\end{array}$} & \multicolumn{2}{|c|}{$\begin{array}{c}F(3, I I 0)=4.70 \\
p<.0 I\end{array}$} \\
\hline
\end{tabular}

Note. Significant pairwise contrasts, $\alpha=.05:{ }^{a}$ secure/fearful; ${ }^{b}$ secure/dismissing; ${ }^{c}$ secure/preoccupied;

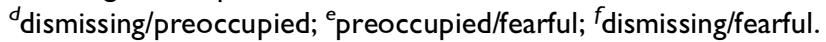

criterion variables not included in the components analysis with extracted components, correlations of these variables with component scores can be used as plot coordinates.

Criterion variables not included in the components analysis were mapped onto the component-loading plot (see Fig. 1). The DAS maps primarily at the secure end of the horizontal axis, anchored by secure subscales on the left and fearful subscales on the right. The IST maps in the upper right quadrant, closest to the region where the preoccupied scales load. The GSI maps along the horizontal axis close to the fearful end, with a slight elevation on the vertical axis toward the preoccupied scales. 
According to Brennan et al. (1998), who analysed 60 attachment subscales, the underlying factor structure for responses on attachment measures is a circumplex. Although conceding that the choice of underlying dimensions is somewhat arbitrary, they suggest using anxiety and avoidance. Given the five attachment measures, Figure 1 shows the approximate positions for the anxiety and avoidance axes, and shows that

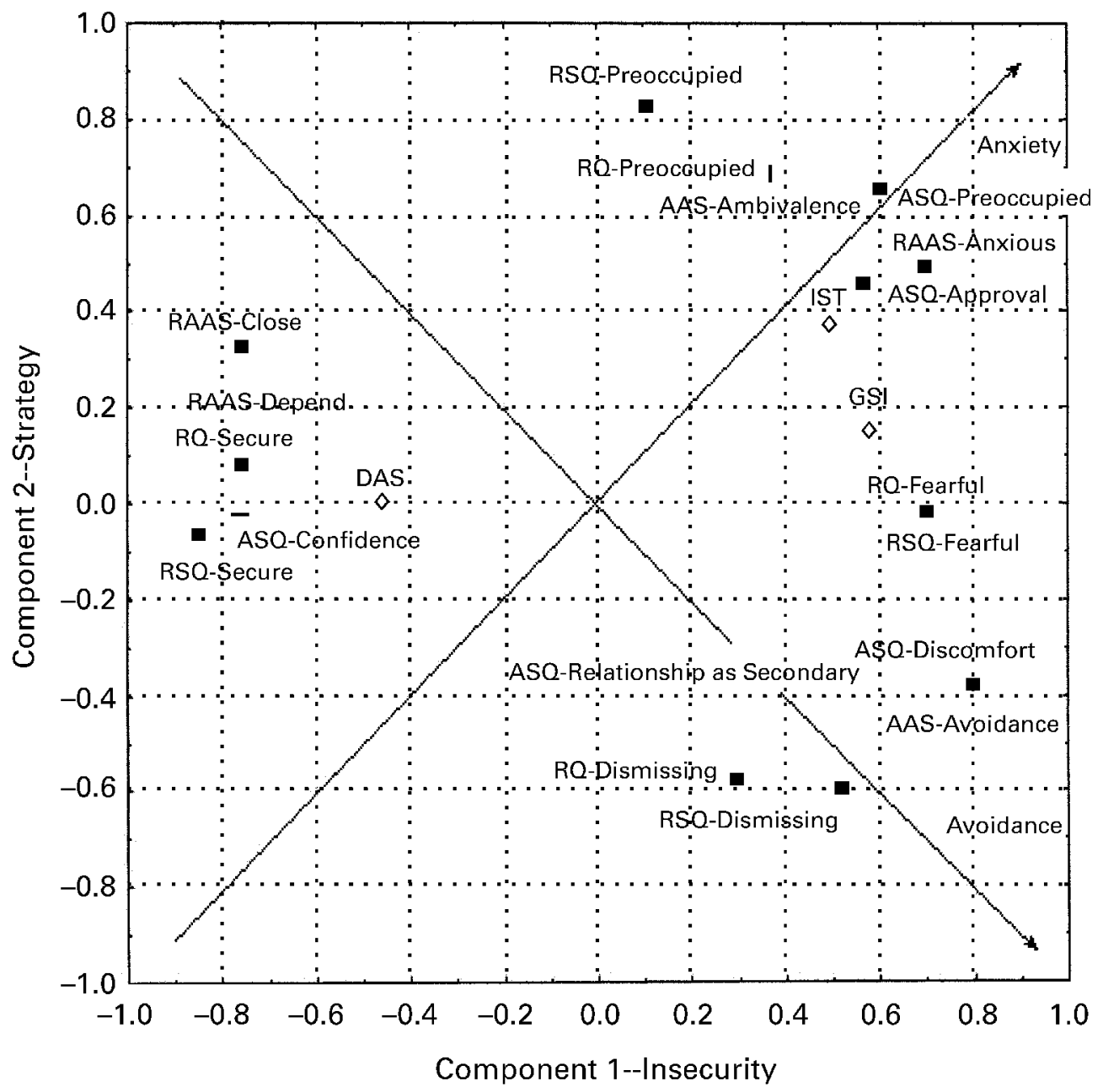

- Scales used in component analysis

\section{- Criterion variables}

Figure I. Plot of correlations with component scores. Note. Subscales of attachment measures and criterion variables are labelled on the plot. Attachment measures include Adult Attachment Scale (AAS), Attachment Style Questionnaire (ASQ), Revised Adult Attachment Scale (RAAS), Relationship Questionnaire (RQ), and Relationship Scales Questionnaire (RSQ). Criterion variables include Global Severity Index (GSI), Interpersonal Sensitivity Scale (IST), and Dyadic Adjustment Scale (DAS). Criterion variables GSI, IST, and DAS mapped closest to fearful/preoccupied, preoccupied and secure, respectively. 
loadings conform to a circular pattern, except for their absence in the lowerleft quadrant. Fearful attachment represents a combination of high anxiety and high avoidance, while secure attachment represents low anxiety and low avoidance. Dismissing attachment is a blend of low anxiety and high avoidance. Preoccupied attachment is a blend of high anxiety and low avoidance.

Another view of attachment's underlying dimensions is suggested by $45 \%$ rotation, which indicates that the horizontal axis represents insecurity ('insecurity'; from secure to fearful), and the vertical axis represents divergent strategies of managing insecure attachment relationships ('strategy'; from preoccupied to dismissing). The correlations of the component scores with criterion variables, GSI, IST and DAS, ${ }^{3}$ illustrate the relationship between these dimensions and the criterion variables (see Table 3 ). The correlations of insecurity with all three criterion variables are significant. Only IST correlated significantly with strategy component scores. Thus, the unrotated twocomponent solution has both a good predictive validity and discriminant validity.

Table 3. Correlations of Component I (secure vs. fearful) and Component 2 (dismissing vs. preoccupied) scores with criterion variable scores (GSI, IST and DAS)

Criterion variables

Components

N GSI

IST

DAS

I. Insecurity (secure vs. fearful)

115

$.58 * *$

$.47^{* *}$

$-.45^{* *}$

2. Strategy (dismissing vs. preoccupied)

115

.16

$.37^{* *}$

.00

** Correlation is significant at $p<.0 \mathrm{I}$ level (two-tailed).

\section{Discussion}

We now address the three questions posed earlier:

(1) Is there agreement between categories across attachment measures, and do categories predict psychological adjustment?

(2) Are there specific associations between underlying dimensions of attachment and specific domains of individual difference, as measured by GSI, IST and DAS?

(3) Do relationships among subscales suggest common underlying dimensions?

We conclude the article by examining implications for further research.

\section{Categorical approach}

We found a modest agreement using a four-way classification system. Our disagreement rates were not appreciably different from those found by Allen et al. (2001). They administered Collins and Read's (1990) Adult Attachment Scale and Bartholomew and Horowitz's (1991) Relationship Questionnaire to a heterogeneous group of women,

\footnotetext{
${ }^{3}$ To test whether the component scores interacted in influencing the criterion variables, we regressed the criterion variables on the component scores as well as a product variable representing their interaction. The interaction effect did not approach significance, so only zero-order correlations of component scores with criterion variables are presented.
} 
including psychiatric in-patients with trauma-related disorders as well as a community sample.

In contrast to Bartholomew and Shaver (1998), we did not find a high agreement between conceptually similar measures. For example, the RQ and RSQ-measures that came from the same research group, were based on a common conceptual framework, and focused broadly on relationships in general-had a disagreement rate of $29 \%$. In contrast, a narrower domain of inquiry was associated with a lower rate of disagreement: the AAS and the RAAS, both of which examine romantic relationships, had the second lowest disagreement rate, $21 \%$. Asking participants to report feelings about 'close relationships' or 'relationships in general' may force them to alter or average their expectations or responses in more socially acceptable ways. Asking about dating or romantic relationships in general, rather than about specific relationships at definite points in time, may still require internal negotiating or averaging. These results suggest that attachment style is not a trait, equally evident across relationships. Yet attachment style remains stable over time, suggesting that it is not completely relationship dependent. Kobak (1999) describes attachment as a transactional process, in that internal working models interact dynamically with the quality of current relationships, so that security is reassessed in that context. Other factors also interact, including nature of the relationship, states of mind evoked, traits of participants, and time period (Allen et al., 2001).

Disagreement across measures probably emanates from another source: most people have a style somewhat at variance with a given prototypic category or with qualities of more than one prototype. Infants at 12 months may exhibit a different attachment pattern with each parent (Steele, Steele, \& Fonagy 1996). Opportunities for multiple attachments increase with development, and concordance of attachment style across relationships remains questionable (Cassidy, 1999). However, attachment theorists traditionally assume that one predominant pattern emerges during development and endures into adulthood in the absence of substantial change in the interpersonal environment (Fonagy, 1999). In classifying participants by their dimensional scores, however, we were impressed by classification dilemmas posed by marginal cases. Some participants scored just above or below one or more cut-off points. Others exhibited discrepancies between subscale scores (e.g. a score on ambivalence substantially higher than the cut-off, along with a score on avoidance just above the cut-off) that could not be reflected by the categorical classification. RQ responses support this point. Although participants had the option of choosing a single style to characterize their relationships, $70 \%$ assigned points to all four styles or classifications, and $28 \%$ to three styles. Only two participants chose a single attachment style. Testing a single measure across a range of specific targets (romantic partner, best friend, mother, father etc.), as suggested by Sperling and Berman (1991), may help clarify whether and under what circumstances individuals have a global attachment style or a set of relationshipdependent styles.

Our finding of relatively high disagreement rates, in the context of many marginal cases classified only with difficulty, argues for a dimensional rather than categorical approach to the measurement of adult attachment. Because participants array themselves dimensionally with respect to any given category and may endorse more than one, measurement systems that can reflect fine distinctions within and across categories may portray adult attachment more accurately.

Three key findings surfaced about the relationships between categories and measures of psychological adjustment. First, higher $F$ ratios were associated with the 
relationship of classification to severity of psychiatric symptoms (GSI) than to scores on the two relational measures (IST and DAS). These results could be owing to the superior reliability of the GSI. The IST is just a subscale of the GSI; the DAS has three questions that may be irrelevant to non-cohabiting couples, the status of just over half our sample. Other interpretations are also possible. For example, a secure individual will not necessarily establish a satisfying relationship or choose someone with few problems. Difficulties in one partner (mental illness, unemployment, addiction, family tragedy or chronic pain) may have a significant negative effect on relationship satisfaction.

Second, security of attachment is also possibly a better index of symptom severity than of interpersonal adjustment, as reflected in our surprising finding that dismissing participants experience a relatively high level of symptoms, but not specifically in the interpersonal arena. That is, dismissing participants' GSI scores are significantly higher than those of the secure group, but their IST scores are significantly lower than those of preoccupied and/or fearful participants. Perhaps the dismissing strategy of independence or detachment offers a successful defence against interpersonal anxiety, although it may not successfully defend against other symptomatology. Crowell, Fraley, and Shaver (1999) note that dismissing individuals are better able to compartmentalize anxiety.

Third, fearful participants had a significantly poorer dyadic adjustment, which can be understood in terms of insecurity and lack of strategy to manage insecure attachment relationships. Secure people have a relatively easy time with close relationships, while dismissing and preoccupied individuals have somewhat adaptive strategies for handling them. In contrast, fearful participants may lack any clear strategy for resolving conflict about their need for and fear of closeness.

\section{Dimensional approach}

If a dimensional model of attachment makes sense, how do the subscales employed by different measures array themselves with respect to common underlying dimensions? As our principal-components analysis and component mapping show, the subscales are moderately to highly correlated as expected and can be interpreted as using the same underlying constructs, avoidance and anxiety, that Ainsworth et al. (1978) postulated. Thus, our findings, like those of Brennan et al. (1998) and Allen et al. (2001), fall into a two-dimensional factor space for attachment. Although Brennan et al's anxiety/ avoidance model has been applied to our component map, the four groups of subscales are not at all equidistant or distinct from one another or from the underlying dimensions as demonstrated by component map positions.

Because the model is based on the rotation of two orthogonal dimensions, the underlying dimensions can be selected for interpretation according to their heuristic value. Our results have given us a springboard for rethinking the conceptual bases of attachment, leading us to question the conventional avoidance-ambivalence model. Instead, we have chosen a model that separates insecurity (Component 1), from secure to fearful, and strategy for coping with insecurity in relationships (Component 2), from preoccupied to dismissing. The first factor (on the horizontal axis of the component map) ranges from secure attachment to a fearful connection with attachment figures. Individuals on the fearful end of Component 1 exhibit more difficulty with close interpersonal relationships, poorer quality of attachment and greater likelihood of psychopathology.

In contrast, the second component, strategy (a vertical axis connecting preoccupied 
subscales and dismissing subscales), spans the different strategies (dismissing to preoccupied) that individuals may use to cope with difficulty in close interpersonal relationships. Although these strategies exemplify two ends of a single component, they are not necessarily polar opposites. Rather, they are different ways to cope with interpersonal difficulty, which may help explain why dismissing and preoccupied subscales do not necessarily have high negative correlations. Birtchnell (1997), who posits attachment as just one form of interpersonal relatedness, notes that detachment can be associated with either security or insecurity. Preoccupation, however, limits individuals from fully participating in appropriately distant relationships.

The relatively weak relationships among attachment measures may actually result from a misconception that preoccupied and dismissing styles reflect insecure vs. secure attachment. What seems more likely is that preoccupied and dismissing attachment represent two alternative strategies for dealing with interpersonal relationships in the absence of an ability to form close, secure relationships (as indexed by the first component). With low insecurity, the need for either dismissing or preoccupied strategies is minimal. With more insecurity comes an increased need for a strategy to manage attachment relationships. At the extreme insecure end of the dimension, adaptive strategies again diminish, from dismissing or preoccupied strategies to no coherent strategy. Thus, there are probably three important positions, conflated until now: low insecurity with no need for special strategy; moderate to high insecurity with specific strategies for sustaining relationships; and extreme insecurity with a disorganized attachment system that precludes strategy. This understanding may explain the gap in an apparent circular pattern of loadings on the component map. Dismissing and preoccupied strategies are equally irrelevant in the context of fully secure attachment.

Viewing attachment in terms of underlying dimensions of insecurity and strategy for coping with insecurity in relationships illuminates our findings on the relationship between individual differences in psychological adjustment (the criterion variables, GSI, IST and DAS) and attachment subscale scores. GSI scores lie on the horizontal axis, the insecurity dimension, correlating significantly with Component 1 (insecurity) but not with Component 2 (strategy) (see Table 3). Dismissing and preoccupied participants have significantly higher GSI and DAS scores as a function of their relative insecurity vs. strategy. Fearful participants, at the low end of Component 1, lack capacity to generate a useful strategy, which increases their vulnerability in intimate relationships. Both insecurity and strategy correlate with interpersonal sensitivity, but high attachment security is not compatible with a troubling degree of interpersonal sensitivity. However, anxious temperament may help define a preoccupied strategy, which may reflect interpersonal sensitivity.

\section{Limitations}

Our findings are limited for several reasons. First, a larger sample would have made them more convincing, and interesting comparisons would have been possible if we had recruited both relationship partners. Second, the measures selected could have been improved. Omitting the 'hedge word' (see footnote 2) in the fearful description of the Relationship Questionnaire would have improved discrimination of fearful attachment. Because the majority of participants were not cohabiting, we could have eliminated three DAS questions that apply only to cohabiting couples. We could have replaced our measure of interpersonal sensitivity, the IST, with a lengthier and more valid measure such as the Inventory of Interpersonal Problems (Horowitz et al., 1988). Because 
dismissing individuals typically under-report psychiatric symptoms, we might have used clinical assessments or peer ratings of psychopathology. Furthermore, component mapping was limited to 18 subscales, in contrast to Brennan et al. (1998), who analysed data from 60 attachment subscales. This limitation may account for gaps in the circular pattern of loadings. Finally, by limiting the comparison of instruments to questionnaires, we excluded fine interviews, most notably the AAI.

\section{Conclusions}

For further study, we recommend using measures that assess attachment dimensionally and specify targets (attachment figures). More research is needed on psychological processes relevant to defining a person's position on the insecurity component underlying attachment. The fuzzy relationship between various types of psychopathology and dismissing and preoccupied attachment may be elucidated by this approach, with psychopathology reflecting high insecurity as opposed to a specific strategy for coping with insecure relationships. Indeed, the second axis reflects individual differences in shutting down vs. hyperactivating the attachment system as a coping strategy in the face of frustrated attachment needs. Thus, studies of attachment strategy in relationship to factors such as temperament and genetics may provide a fruitful direction for further research.

\section{Acknowledgements}

The authors would like to thank Noel J. Jacobs, Kathleen Ferguson and Molly Wisman for their help in administering questionnaires to research participants. Appreciation is due to three anonymous reviewers.

\section{References}

Ainsworth, M. D. S., Blehar, M. C., Waters, E, \& Wall, S. (1978). Patterns of attachment: A psychological study of the strange situation. Hillsdale, NJ: Erlbaum.

Allen, J. G., Huntoon, J., Fultz, J., Stein, H, Fonagy, P., \& Evans, R. B. (2001). A model for brief assessment of attachment and its application to women in inpatient treatment for traumarelated disorders. Journal of Personality Assessment, 76, 421-447.

Bartholomew, K. (1990). Avoidance of intimacy: An attachment perspective. Journal of Social and Personal Relationships, 7, 147-178.

Bartholomew, K., \& Horowitz, L (1991). Attachment styles among young adults: A test of a four category model. Journal of Personality and Social Psychology, 61, 226-244.

Bartholomew, K., \& Shaver, P. R. (1998). Methods of assessing adult attachment: Do they converge? In J. L Simpson \& W. S. Rholes (Eds.), Attachment theory and close relationships (pp. 25-45). New York: Guilford.

Birtchnell, J. (1997). Attachment in an interpersonal context. British Journal of Medical Psychology, 70, 265-279.

Bowlby, J. (1969/1982). Attachment and loss: Vol. I. Attachment. New York: Basic Books.

Brennan, K. A., Clark, C. L, \& Shaver, P. R. (1998). Self-report measurement of adult attachment. An integrative overview. In J. A. Simpson \& W. S. Rholes (Eds.), Attachment theory and close relationships (pp. 46-75). New York: Guilford.

Cassidy, J. (1999). The nature of the child's ties. In J. Cassidy \& P. R. Shaver (Eds.), Handbook of attachment: Theory, research, and clinical applications (pp. 3-20). New York: Guilford. 
Collins, N. L (1996). Working models of attachment: Implications for explanation, emotion, and behavior. Journal of Personality and Social Psychology, 71, 810-832.

Collins, N L, \& Read, S. J. (1990). Adult attachment, working models, and relationship quality in dating couples. Journal of Personality and Social Psychology, 58, 644-663.

Cooper, M. L, Shaver, P. R, \& Collins, N. L (1998). Attachment styles, emotion regulation, and adjustment in adolescence. Journal of Personality and Social Psychology, 74, 1380-1397.

Crowell, J., Fraley, R. C., \& Shaver, P. R. (1999). Measurement of individual differences in adolescent and adult attachment. In J. Cassidy \& P. R. Shaver (Eds.), Handbook of attachment: Theory, research, and clinical applications (pp. 434-465). New York: Guilford.

Derogatis, L R. (1993). Brief Symptom Inventory: Administration, scoring, and procedures manual. Minneapolis, MN: National Computer Systems.

Dozier, M. \& Lee, S. W. (1995). Discrepancies between self- and other-report of psychiatric symptomatology: Effects of dismissing attachment strategies. Development and Psychopathology, 7, 217-226.

Feeney, J. A. (1994). Attachment style, communication patterns and satisfaction across the life cycle of marriage. Personal Relationships, 1, 333-348.

Feeney, J. A. Noller, P., \& Callan, V. J. (1994). Attachment processes in adulthood. In K. Bartholomew \& D. Perlman (Eds.), Advances in personal relationships (Vol. 5, pp. 269308). Bristol, PA: Jessica Kingsley.

Feeney, J. A, Noller, P., \& Hanrahan, M. (1994). Assessing adult attachment. In M. B. Sperling \& W. H. Berman (Eds.), Attachment in adults: Cinical and developmental perspectives (pp. 122-158). New York: Guilford.

Fonagy, P. (1999). Psychoanalysis and attachment theory. In J. Cassidy \& P. R. Shaver (Eds.), Handbook of attachment: Theory, research, and clinical applications (pp. 595-624). New York: Guilford.

Fraley, R. C., \& Waller, N. G. (1998). Adult attachment patterns: Atest of the typological model. In J. A Simpson \&W. S. Rholes (Eds.), Attachment theory and close relationships (pp. 350-365). New York: Guilford.

George, C. Kaplan, N., \& Main, M. (1996). Adult attachment interview (3rd ed.). Unpublished manuscript, Department of Psychology, University of California, Berkeley.

Griffin, D. W., \& Bartholomew, K. (1994). The metaphysics of measurement: The case of adult attachment. In K. Bartholomew \& D. Perlman (Eds.), Advances in personal relationships: Vol. 5. Attachment processes in adulthood (pp. 17-52). London: Jessica Kingsley.

Harman, H H (1967). Modern factor analysis. Chicago: University of Chicago Press.

Hazan, C., \& Shaver, P. R. (1987). Romantic love conceptualized as an attachment process. Journal of Personality and Social Psychology, 52, 511-524.

Hazan, C., \& Shaver, P. R. (1994). Authors' response: Deeper into attachment theory. Psychological Inquiry, 5, 68-79.

Horowitz, L M. Rosenberg, S. E., Baer, B. A. Ureño, G., \& Villaseñor, V. S. (1988). Inventory of Interpersonal Problems: Psychometric properties and clinical applications. Journal of Consulting and Cinical Psychology, 56, 885-892.

Kirkpatrick, L A. \& Davis, K. E (1994). Attachment style, gender, and relationship stability: A longitudinal analysis. Journal of Personality and Social Psychology, 66, 502-512.

Kobak, R. (1999). The emotional dynamics of disruptions in attachment relationships: Implications for theory, research, and clinical intervention. In J. Cassidy \& P. R. Shaver (Eds.), Handbook of attachment: Theory, research, and clinical implications (pp. 21-43). New York: Guilford.

Rutter, M. (1995). Clinical implications of attachment concepts: Retrospect and prospect. Journal of Child Cinical Psychology and Psychiatry, 36, 549-571.

Simpson, J. (1990). Influence of attachment styles on romantic relationships. Journal of Personality and Social Psychology, 59, 971-980.

Simpson, J., Rholes, W. S., \& Phillips, D. (1996). Conflict in close relationships: An attachment perspective. Journal of Personality and Social Psychology, 71, 899-914. 
Spanier, G. B. (1976). Measuring dyadic adjustment: New scales for assessing the quality of marriage and similar dyads. Journal of Marriage and the Family, 38, 15-28.

Sperling, M. B., \& Berman, W. H (1991). An attachment classification of desperate love. Journal of Personality Assessment, 56, 45-55.

Sperling, M. B., Foelsch, P., \& Grace, C. (1996). Measuring adult attachment: Are self-report instruments congruent? Journal of Personality Assessment, 67, 37-51.

Steele, H, Steele, M. \& Fonagy, P. (1996). Associations among attachment classifications of mothers, fathers, and their infants. Cild Development, 67, 541-555.

Stein, H, Koontz, A. D., Allen, J. G., Fultz, J., Brethour Jr., J. R., Allen, D., Evans, R. B., \& Fonagy, P. (2000). Adult attachment questionnaires: Disagreement rates, construct and criterion validity (Technical Report No. 00-0023). Topeka, KS: The Menninger Clinic, Research Department.

Received 26 September 2000; revised version received 8 October 2001 